\title{
Entre o passado e o futuro: o que o presente dos beneficiários do Programa de Volta para Casa ensina sobre o programa
}

\author{
Between past and future: what the everyday lives of beneficiaries \\ of brazil's Back Home Program teach us about the program
}

Paula Andréa Massa (https://orcid.org/0000-0002-8807-421X) ${ }^{1}$

Enrique Araujo Bessoni (https://orcid.org/0000-0003-0521-1627) ${ }^{1}$

Maria Inês Badaró Moreira (https://orcid.org/0000-0001-5798-2023) ${ }^{2}$
${ }^{1}$ Programa Interdisciplinar em Ciências da Saúde, Universidade Federal de São Paulo. Rua Silva Jardim 136, Edifício Central. 11015-020 Santos SP Brasil. paulamassa81@gmail.com ${ }^{2}$ Departamento de Políticas Públicas e Saúde Coletiva, Universidade Federal de São Paulo. Santos SP Brasil.

\begin{abstract}
This study investigates the everyday lives of six beneficiaries of the Programa de Volta para Casa (the "Back Home Program" - PVC) with the aim of analyzing its effects and identifying lessons that can be applied to help improve and ensure the continuity of the deinstitutionalization process in dialogue with the current political, social and economic reality. Using participant observation and narratives, we conducted a qualitative study in two cities that have been implementing the PVC over the last 15 years. The results were organized into the following core themes: the participants - who they are and how they live; the challenges of being back in the city; using money and the challenge of shifting towards social capital; and the guarantee of rights. The findings of the hermeneutic-dialectic analysis show that the beneficiaries have moved away from a situation of zero contractuality and ruptured affective relations towards one of access to goods and services, housing and free movement in public spaces, limited by urban violence, lack of money for leisure activities, aging, precarious housing conditions, and lack relations of trust and solidarity with ordinary people living in the neighborhood. Making the city an enabling environment and promoting actions in coordination with other sectors such as housing, income, employment, security and justice are steps of resistance in the face a regressive political, economic and social landscape. Key words Deinstitutionalization, Mental health, Personal narrative, Citizen participation in science and technology
\end{abstract}

Resumo O estudo revela o cotidiano de seis beneficiários do Programa de Volta para Casa (PVC) com o objetivo de analisar seus efeitos e apontar aprendizados para a atualização e a continuidade do processo de desinstitucionalização em diálogo com a realidade política, social e econômica. Pesquisa qualitativa com uso de observação participante e narrativas realizada em dois municípios com PVC há 15 anos. Os resultados foram organizados em cinco eixos temáticos que versam sobre quem são e como vivem, os desafios de estar de volta à cidade, o uso do capital monetário e o desafio da sua passagem para capital social e a garantia de direitos. A análise hermenêutica-dialética mostra que os beneficiários do PVC partem de um lugar de contratualidade zero e rompimento de seus vinculos de afeto e passam a ter acesso a bens, serviços, moradia e a circulação pelos espaços públicos, ainda limitada pela violência urbana, a falta de recurso para financiar atividades de lazer, o envelhecimento, a precariedade da moradia e a falta de relação de confiança e solidariedade com pessoas do bairro. Habilitar a cidade e a articulação intersetorial com habitação, renda, trabalho, segurança e justiça são passos de resistência em um cenário político, econômico e social de retrocesso.

Palavras-chave Desinstitucionalização, Saúde mental, Narrativa pessoal, Participação cidadã em ciência e tecnologia 


\section{Introdução}

O Programa de Volta para Casa (PVC), regulamentado pela Lei 10.708, de 31 de julho de $2003^{1}$, é uma aposta vanguardista da Reforma Psiquiátrica Brasileira. Definido como auxílio reabilitação psicossocial, institui o repasse de um benefício mensal, diretamente às pessoas egressas de longas institucionalizações psiquiátricas. Uma de suas peculiares características é que, ao exigir documentação civil para cadastro e abertura de conta bancária pessoal, também contribui para a recuperação dos registros civis perdidos, tais como certidão de nascimento e CPF e, consequentemente, para o resgate da história de pessoas que tiveram uma vida negada.

Este programa brasileiro é único no seu caráter de pagamento direto à pessoa cadastrada, pois não há registro de outra iniciativa deste porte. Nos processos de desinstitucionalização que ocorreram em outros países, geralmente, o recurso é destinado a financiamento de serviços e programas. Ações do programa italiano, o budget di salute, pode ser a experiência mais próxima ao PVC, pois também tem o objetivo de responder demandas financeiras de egressos de internações psiquiátricas. Entretanto, seu objetivo principal é financiar projetos personalizados ${ }^{2}$. É semelhante por ser preconizado em função de uma pessoa, mas diferente por não ser pago diretamente à pessoa, como no Brasil.

Com esse aspecto tão singular, é surpreendente como o PVC é pouco estudado, dentre todas as estratégias desenvolvidas e implantadas na Reforma Psiquiátrica Brasileira ${ }^{3}$. As publicações apresentadas a seguir revelam o impacto que a inclusão neste programa promove na vida cotidiana de seus beneficiários, assim como os desafios relacionadas ao seu acesso.

Dentre as publicações encontradas, destacam-se as experiências de Fortaleza ${ }^{4}$ e Belo Horizonte $^{5}$ que descrevem a contribuição do PVC para a desospitalização de pessoas em longa internação psiquiátrica. Ser um beneficiário do PVC é um exercício de cidadania por que foi garantido o direito civil de ter documentos, o que antes não tinham; o direito de ir e vir como moradores da cidade e não do hospital psiquiátrico; o direito político de ter título de eleitor e o direito social por acessar essa política pública ${ }^{4}$. Concluíram que o PVC foi o que tornou possível esse processo de resgate de diversos direitos ${ }^{5}$.

Em relação à contribuição do programa para ações de reabilitação psicossocial, Lima ${ }^{4}$ identificou existir grande desafio na associação entre a participação no programa e os projetos de vida de seus beneficiários. A justificativa é o desconhecimento sobre o PVC por parte da equipe técnica. Além disso, aponta a necessidade de acompanhamento do uso do benefício com vistas ao exercício da cidadania. A análise do processo de implementação do PVC em Ribeirão Preto ${ }^{6}$, na perspectiva dos gestores, descreve um cenário diferente em que o uso do dinheiro é feito pelos beneficiários com apoio da equipe de saúde mental, o que denomina como cidadania assistida, por combinar ações de tutela e de promoção da autonomia de acordo com a necessidade do usuário.

Muitos beneficiários do PVC são também moradores do Serviço Residencial Terapêutico (SRT), que são alternativas de moradia para um grande contingente de pessoas que foram internadas em hospitais psiquiátricos e tiveram seus laços familiares e comunitários rompidos ${ }^{7}$. Ao explorar a forma como o recurso financeiro é utilizado pelos beneficiários, os estudos retratam experiências de utilização em atividades de lazer, reforma da casa, compra de móveis e o pagamento de serviços de saúde não acessados no SUS, como por exemplo, órtese e prótese dentária ${ }^{5,6}$.

Em um SRT localizado em Salvador, parte do auxílio é utilizado de forma coletiva, ou seja, para cobrir os gastos que não são supridos pelo recurso financeiro destinado à implantação e manutenção dos SRT. A outra parte é disponibilizada semanalmente aos beneficiários e a gestão é feita pelo cuidador do SRT ${ }^{8}$. Realidade diferente é vivida por moradores de SRT e beneficiários do PVC de uma cidade da grande São Paulo que rotineiramente acessam estabelecimentos comerciais, sobretudo relacionados à disponibilidade de alimentos (feira, restaurante, padaria, supermercado, banco, lotérica, salão de beleza, shopping), seguidos dos espaços de cultura e lazer (praia, pesqueiro, pinacoteca, igreja, estádio de futebol, cinema) e, por último, os serviços de saúde?

As produções mais recentes sobre o PVC são fruto de uma avaliação nacional, coordenada pela Fiocruz Brasília e com apoio de professores/as universitários/as de instituições de cinco estados brasileiros. Guerrero et al. ${ }^{10}$ ressaltam a efetiva promoção de ganhos individuais aos beneficiários do PVC com a promoção da inserção social, cidadania e aumento de poder contratual de forma mais potente, quando articulado à rede de serviços e aos territórios das pessoas. Em complemento, Bessoni et al. ${ }^{11}$, a partir da análise de narrativas construídas durante a avaliação nacional, afirmam que a associação entre diferentes 
estratégias da Reforma Psiquiátrica Brasileira: PVC, Centro de Atenção Psicossocial (CAPS) e SRT possibilitou

o estabelecimento de relações afetivas, à circulação na cidade, ao consumo de bens e serviços e, consequentemente, maior capacidade de expressão, comunicação e posicionamento crítico. Foi possivivel observar novas esferas de negociação engendradas pelo recebimento do dinheiro ${ }^{11}$ (p. 40).

Existem, no Brasil, 4520 beneficiários do $\mathrm{PVC}^{12}$. Apesar dos benefícios relacionados às garantias de direito em razão do acesso ao programa, os números apontam para um quantitativo relevante de pessoas que poderiam, mas não são cadastradas no PVC. De acordo com a inspeção nacional feita em $2019^{13}$ em hospitais psiquiátri$\cos , 14 \%$ dos leitos são ocupados por moradores, ou seja, há ainda aproximadamente 3.639 potenciais beneficiários do PVC morando em hospitais psiquiátricos.

Estes dados mostram que os avanços no campo da reforma psiquiátrica estavam iniciados, mas não finalizados. Os caminhos para seu fortalecimento pareciam estar sendo construídos por meio da ampliação da RAPS, como por exemplo com a criação e expansão do PVC durante a primeira década dos anos 2000. Entretanto, a partir de 2016, houve mudanças no cenário político, tais como: impeachment da presidente, judicialização da saúde que contribuiu para o atraso nas parcelas do PVC, criação da PEC 241 congelando gastos públicos com saúde e educação para os próximos $20 \operatorname{anos}^{14} \mathrm{e}$ a ascensão da extrema direita na gestão pública federal.

Moreira et al..$^{15}$ apontam para os desafios impostos à Reforma Psiquiátrica Brasileira neste contexto que teve como consequência o incentivo ao modelo hospitalocêntrico e a insustentabilidade de políticas públicas de saúde e sociais. Assim, faz-se de extrema importância, identificar os ganhos, avanços e desafios dos programas governamentais para que a avaliação sobre a sua continuidade e ou expansão, inclusive sobre como fazer, possam ser subsidiadas também pela perspectiva de quem são seus beneficiários.

O objetivo deste artigo é refletir sobre os efeitos do Programa de Volta para Casa no cotidiano das pessoas beneficiárias. Sendo assim, parte da identificação das necessidades e demandas que apresentam para se manterem em liberdade. Para além disso, aponta o que se pode aprender para a atualização e continuidade do processo de desinstitucionalização, especificamente em relação ao PVC. Por fim, discute esses achados em diálogo com a realidade política, social e econômica atual.

\section{Metodologia}

Este artigo é fruto de dois estudos convergentes, cujos municípios escolhidos possuem algumas semelhanças: são de médio porte e foram sede de hospitais psiquiátricos de referência regional, por isso pioneiros na implantação do PVC. Mesmo que em regiões diferentes do país, Nordeste e Sudeste do Brasil foram potências nos processos de desinstitucionalização. Outra convergência é que ambos partiram de pesquisa qualitativa, assentada no campo da Saúde Mental, que explorou a realidade social e o cotidiano da vida das pessoas beneficiárias do Programa de Volta para Casa, ou seja, uma existência inaugurada com a possibilidade de viver em liberdade, após anos de confinamento e isolamento em hospitais psiquiátricos.

Para Minayo, a pesquisa qualitativa se apresenta como um dos produtos "das interpretações que os humanos fazem a respeito de como vivem, constroem seus artefatos e a si mesmos, sentem e pensam"16 (p. 57). As técnicas utilizadas nesses estudos foram a observação participante que permite conhecer uma "variedade de situações ou fenômenos que não são obtidos por meio de

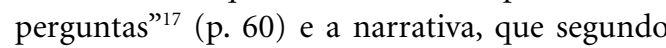
Koosah et al. ${ }^{18}$, é importante instrumento para mediar autoria de vida e para compreensão dos desafios do cuidado e da produção de conhecimento, no contexto da Reforma Psiquiátrica Brasileira. Apontam que o encontro entre as pessoas egressas de longas internações psiquiátricas e um grupo de pesquisadoras, no cotidiano das cidades-campo da pesquisa, reflete a complexidade dos encontros humanos, diferentemente da relação hierárquica que comumente se estabelece entre pesquisador e pesquisado.

As narrativas sobre cada participante construídas após quatro encontros de observação participante, apresentam quem são, o que o dinheiro faz poder e como se relacionam com as pessoas e bairros em que moram. Nesse método a fala dos atores sociais, no caso transcritas em narrativas pelo grupo de pesquisadores, são situadas em seu contexto para serem melhor compreendidas.

Para este artigo, cada pesquisador revisitou suas narrativas para selecionar trechos que subsidiassem as reflexões sobre como os determinantes fundamentais: conjuntura socioeconômica e política se relacionam com as demandas e necessidade percebidas no cotidiano dos beneficiários e assim construir reflexões acerca da continuidade do programa no cumprimento do seu objetivo: a reabilitação psicossocial. A escolha das narrativas foi feita por sorteio, três de cada projeto 
de pesquisa, sem pré-requisito, para minimizar as tendências na análise.

Em seguida, houve a releitura das narrativas com trechos selecionadas de modo que um pesquisador validasse a seleção feita pelo outro. Os trechos foram analisados conjuntamente com base na perspectiva hermenêutica-dialética ${ }^{14,19} \mathrm{e}$ utilizados para ilustrar os eixos que emergiram no encontro entre a historicidade da vivência dessas pessoas e a fundamentação teórica.

Os estudos foram aprovados pelo Comitê de Ética sob os pareceres número 3.243.147 e 2.064.899.

\section{Resultados e discussão}

Os resultados foram organizados em cinco eixos que versam sobre quem são e como vivem os participantes, os desafios de estar de volta à cidade, $\mathrm{o}$ uso do capital monetário e o desafio da sua passagem para capital social e a garantia de direitos.

\section{Quem são as pessoas e como vivem na cidade}

A análise das transformações parte de uma breve apresentação de cada um, das perdas relativas ao período de internação e chega em como estão vivendo atualmente.

Estevão é um homem negro, altura mediana, cabelo curto, cacheado e grisalho, nascido no interior de São Paulo e morador do litoral desde tenra idade quando ainda mamava no peito. Viveu longo período de internação, entretanto não sabe dizer com exatidão quantos anos passou internado, mas sabe que foi "uma vida, um grande tempo" que ele não pôde estar com os seus. Perdeu a casa do pai e da avó para os primos que permaneceram nela. Hoje tem 61 anos, mora sozinho e frequenta diariamente o CAPS para, em suas palavras, fazer a sua diversão: tocar violão. É conhecido por sua atitude cordial e gentil. Mensalmente vai ao banco para sacar o dinheiro que paga as despesas da casa e o dinheiro miúdo que sobra usa na padaria para tomar alguma coisa e passa no débito, por achar perigoso ficar com muito dinheiro no bolso. As moedas ficam para comprar o cigarro solto. Suas últimas compras foram os óculos e o celular.

Janaína tem 54 anos, é geminiana, fala baixo, é calma e a princípio desconfiada, mas depois gosta de falar de si. Identifica-se como uma morena cor de jambo. Passou por várias internações por causa das suas quedas que a fazem perder a consciência, contou que fugiu do último hospital "sem estar curada e faz quase dois anos que não interna”. Frequenta diariamente o CAPS, faz suas refeições, pois em casa pouco cozinha, faz lanche. Costumava participar da oficina de artesanato, mas hoje prefere assistir televisão. Tem um celular companheiro para ouvir os hinos que ouvia quando frequentava a igreja evangélica Congregação Cristã do Brasil aos domingos.

Wando morou na rua, no educandário, no hospital, passou por vários, só no último ficou por 5 anos. Hoje tem 61 anos e mora sozinho em uma casa alugada e a define como a coisa mais linda, com caixas de som. Circula pelo bairro com um aparelho de som da Aiwa e um pen-drive com músicas do Roberto Carlos, seu cantor preferido. Vai diariamente para o CAPS, se alimenta e volta para casa de ônibus. "Faça chuva, faça sol", é pontual em sacar o benefício, pagar o aluguel, água e luz. Utiliza o PVC para as compras de mercado, prefere ir ao do bairro e não no grande da avenida, por que é mais barato.

Ninha passou 27 anos internada, teve três filhos durante este período, mas desconhece o paradeiro deles; além de ter dois irmãos, com quem tem pouco contato. Demonstrou imediata compreensão dos objetivos da pesquisa, ajudando a indicar quem e onde encontrar possíveis participantes, revelando amplo conhecimento do dia a dia dos demais beneficiários e da cidade. Participante do grupo de dança e do projeto de geração de renda, aceitou participar, desde que se atentassem aos seus horários "porque faço muita coisa pela manhã, em casa, e a tarde também, pela cidade".

Linda, 68 anos, reside em SRT, foi internada inúmeras vezes, desde criança, tem registro apenas do período de sua última internação, que durou sete anos. Teve dois filhos e três netos, com quem encontrou apenas em algumas festas de final de ano. Conviveu mais com as demais moradoras da casa, especialmente Lí, sua amiga desde os tempos de internação. Com sua saúde já debilitada, Linda faleceu dois meses após o encerramento do campo da pesquisa.

Zé, por volta dos 50 anos, é um homem negro, gosta de estar sempre bem arrumado, contrapondo aos vários períodos de internação, sendo o último em uma comunidade terapêutica, de onde saiu após sete anos para morar em uma SRT. Tem certeza de ter a data de nascimento registrada errada, antes das internações chegou a se casar duas vezes e ter uma filha, mas não tem vínculos familiares. Trabalhou formalmente uma única vez. Segundo ele, foi a bebida que o levou 
a ter problemas. Mesmo com medo, de se perder principalmente, gosta dos passeios com demais moradores, de ir a um restaurante da cidade e de tomar sorvete.

Apresentados os protagonistas, partimos para o relato das necessidades e demandas identificadas nas narrativas como subsídio para a compreensão dos desafios de sustentar a desinstitucionalização e a reabilitação psicossocial em curso. Consideramos este um processo que altera o circuito psiquiátrico constituído como modelo societal em busca de constante e diária inclusão social tendo a centralidade na vida do indivíduo ${ }^{20}$, diferentemente da versão limitada e equivocada, que propõe um processo de desospitalização ou de humanização do cuidado em espaços asilares como um processo de aprendizagem, criticadas por Venturini ${ }^{20}$ e Pitta ${ }^{21}$

\section{Os desafios do estar de volta}

Percebe-se nas seis histórias que o rompimento das relações de afeto existentes antes do longo período de internação, para todos, foi definitivo. Ao retomar a vida, foi possível encontrar tanto nos trabalhadores quanto frequentadores do CAPS ou moradores do SRT, novos laços de amizade e parcerias. Para alguns dos participantes, foi possível escolher quem seria seu profissional de referência do CAPS, escolha improvável em tempos vividos entre muros. Como moradores da cidade, em liberdade, inaugura-se a possibilidade de se relacionar, de estar com o outro como opção, ao perceber interesses comuns frente aos demais, e não por obrigação como nas instituições fechadas. Wando e Janaína relatam o estabelecimento de outros laços, com os amigos do antigo trabalho e da Igreja, respectivamente.

Estevão, Janaína e Wando moram sozinhos, com isso, a circulação na cidade ocorre diariamente. Os itinerários são parecidos e rotineiros: de casa para o CAPS, mercados, banco, comércio em geral e andanças pelo bairro. As voltas e as paradas no trajeto estão relacionadas às atividades comuns de quem vive na cidade: fazer compras e pagar as contas. Para Linda, Zé e Ninha, que moram em SRT, a circulação na cidade parece ser menos frequente e rotineira, mas variada, por ser um trajeto de passeio. Ninha, em especial, tem uma rotina de trocas sociais bastante ampliada ao vender os seus produtos na rua durante as manhãs.

Embora haja ampliação, a expansão desses itinerários é limitada por diferentes contornos: "o dinheiro não dá pra nada, no dia que recebo o 'de volta pra casa' vou passear na praia, só para olhar.” (Estevão); “alguém pode me pegar no caminho, se alguém chegar e dizer me dá 10 reais senão você não passa, o que eu vou poder fazer? Vou ter que dar os 10 reais (...) não gosto de ir para lugar nenhum, tenho medo de alguém fazer uma maldade comigo (...) receber choque e levar uma cacetada" (Wando). Linda tem diabetes e costuma estar com as pernas inchadas, a rua íngreme torna-se uma limitação. Ninha preocupase com o fato de a rua ser pouco movimentada e com os assaltos que ouviu falar e Zé não costuma sair sozinho porque pode se perder ou cair e não receber ajuda, assim como Janaina: "tenho medo de andar sozinha pela cidade e se eu cair e perder a consciência?"

A violência urbana, a falta de recurso para atividades de lazer e a limitação física, decorrente do envelhecimento, parecem ser obstáculos à circulação social entre pessoas acima dos 60 anos e consequentemente um dos principais dificultadores da reabilitação psicossocial, como também concluiu Campos ${ }^{6}$. O histórico de isolamento social e o estigma sofrido por egressos de internação psiquiátrica de longa permanência podem explicar o medo dos participantes em estabelecer novas relações sociais. Parecem se sentir mais susceptíveis a alguma situação de violência ou até mesmo em não receber socorro, caso precisem.

É importante ressaltar que os contornos trazidos não estão relacionados as limitações decorrentes do sofrimento psíquico, mas pelo fato de serem pessoas idosas, privadas de liberdade em grande parte de sua vida adulta em uma sociedade com altos índices de violência e desigualdade social.

$\mathrm{Na}$ perspectiva de Venturini ${ }^{20}$, pode-se afirmar que de fato houve um processo de desinstitucionalização quando há a outorga das capacidades civis, sociais e individuais e a cidade passa a ser conjunto de roteiros, trocas, itinerários estabelecidos por cada um e entre as pessoas. A efetiva desinstitucionalização prevê transformações e trocas sociais entre as pessoas que nela vivem.

\section{O capital monetário e a cidade}

Das experiências de uso do dinheiro, duas questões emergiram: as diferentes estratégias de apoio aos beneficiários para acesso e uso deste recurso e a relação predadora que pessoas ou instituições como banco e lojas estabelecem.

A primeira questão é vivenciada entre profissionais de saúde e os beneficiários. Podem ser estratégias para o acesso ao recurso: guardar os 
documentos, cartão e senha para garantir que eles não se percam ou sejam roubados, fazer o saque em nome do beneficiário, acompanhar no trajeto para fazer o saque, estar junto no momento da retirada e ensinar como operar a máquina do banco. Podem ocorrer também na gestão do recurso ao longo do mês: guardar o dinheiro para apoiar no controle, fazer as contas das despesas e o que sobra para outros gastos, informar quanto tem guardado, verificar se existe saldo para uma compra maior, assim como analisar as prioridades frente a quantidade de recursos.

Para os que residem em casas alugadas, a relação com o CAPS parece ser de constante negociação. Wando deixa seus cartões e documento de identificação original no seu prontuário e todo dia 20 lembra sua técnica de referência que é o dia de ir com ele à lotérica. Caminham juntos os três quarteirões entre o CAPS e a lotérica e ao chegar Wando sabe o que deve fazer: digitar a senha, guardar o dinheiro na pochete ainda dentro da lotérica e ir direto pagar suas dívidas. Janaína explica que depois que aprendeu com a equipe do CAPS a sacar o dinheiro, passou a ir sozinha. Ao longo do mês, faz sua lista do supermercado e da farmácia, assim, quando recebe, consegue ir direto fazer suas compras. Quando sobra, passa na loja de roupa e calçado. Estevão fica com seus documentos e cartões e assim faz seus saques e compras no cartão de débito. Como já perdeu seus documentos algumas vezes, optou por deixar uma cópia no seu prontuário, caso precise fazer uma segunda via.

Quanto aos moradores de SRT, parte do recurso vai para a caixinha que paga as despesas compartilhadas da casa. Linda não vai ao banco, prefere que seu cartão e senha fiquem com a sua profissional de referência e que a cuidadora faça os saques por ela. Zé não costuma ir ao banco sacar e explica como faz o uso do seu benefício: "Mas tem dinheiro que é pra guardar, e dinheiro que é pra gastar. Antes eu não tinha nenhum pra guardar, agora eu guardo muito e gasto pouco". Com suas economias, faz algumas aquisições, tais como móveis, CD e aparelho de som. Além disso, costuma pagar por consultas médicas quando não consegue acesso ao SUS. Ninha tem autonomia no acesso ao recurso e recebe ajuda no controle financeiro. Uma das cuidadoras da SRT guarda o seu benefício e ao longo do mês fragmenta o recurso para pagar a unha que faz no salão, o plano de saúde ou comprar um picolé, por exemplo. Foi com este apoio que conseguiu economizar para adquirir câmera fotográfica, celular e ventilador. Conclui que "esse dinheiro do De Volta Pra Casa ajuda demais (...) se a pessoa ficar sem receber esse dinheiro fica tudo sem nada. Tudo liso (...) quer se manter e não pode".

A vida na cidade impõe riscos, neste sentido, a segunda questão que se destaca é a relação predadora entre pessoas e instituições com os beneficiários e são exemplificadas pelos episódios e falas a seguir.

Durante a caminhada para a retirada de seu benefício acompanhado de uma profissional do CAPS, Wando foi abordado por um homem que ofertou uma vaga em Comunidade Terapêutica para tratamento de alcoolismo. Apesar da recusa, o homem os acompanha argumentando sobre os benefícios desse investimento.

Janaína não conseguiu comprar uma televisão porque seu nome está sujo. Explica que nunca fez empréstimo no banco, mas os seus cartões das lojas de departamentos estão com parcelas em aberto e sua dívida se aproxima a $\mathrm{R} \$ 4$ mil. Também conta sobre um vizinho que ele lhe ensinou a fazer transferência bancária para que ela lhe emprestasse dinheiro. Zé contou, com baixo tom de voz, sobre um assalto ocorrido no SRT. Os dois homens levaram todo o dinheiro que havia guardado no cofre, $\mathrm{R} \$ 100$ que cada morador dá todos os meses para custear as despesas comuns, "mas eles não machucaram ninguém".

No banco, Estevão se surpreendeu com a ausência de saldo em sua conta. O gerente explicou que a diferença era da parcela de um título de capitalização de $\mathrm{R} \$ 100$, adquiridos quando o gerente o explicou que era importante guardar dinheiro. Estevão ficou sem entender como guardar dinheiro seria uma boa escolha, se não teria como pagar o aluguel, então pediu que o título fosse cancelado. Ficou surpreso e preocupado quando descobriu que ele só poderia acessar esse dinheiro daqui um ano.

Ao longo dos trechos citados é possível perceber os desafios de estar de volta na cidade. $\mathrm{Na}$ experiência dos que moram em uma SRT, a moradia garantida, faz poder ir além, sem se endividar, diferentemente do ocorre com Wando, Janaina e Estevão que moram sozinhos e, apesar de também receberem o LOAS (Benefício de Prestação Continuada), têm dificuldade em sustentar a sua moradia e necessidades básicas.

O orgulho pela conquista de morar sozinho é consequência de uma virada entre uma experiência de contratualidade zero ${ }^{22}$ enquanto moradores de um hospital psiquiátrico para um lugar de alguma contratualidade na condição de moradores da cidade. Os dados contribuem para compreender como essa política pública respon- 
de diretamente às necessidades do indivíduo que viveu período de exclusão e isolamento.

Depois do orgulho, o desejo por moradia melhores é um sentimento comum e pode ser percebido nas falas sobre a aparência de sua casa: "bagunçada com coisas velhas, sem janela, com goteiras" (Wando), "tem sujeira e bagunça” (Janaína), "é pequeno, não cabe tudo, fica impossível de limpar” (Estevão). Sentimento que só se faz possível quando vivenciam este lugar de contratualidade em que passam a ter consciência sobre sua condição de excluídos socialmente, por não acessar direitos básicos, como por exemplo, ter uma moradia digna, definida na constituição como aquela que dispõe de instalações sanitárias adequadas, que garanta as condições de habitabilidade.

Venturini $^{23}$ assinala que, para o avanço do processo de desinstitucionalização, se faz necessário conhecer a cidade, os recursos e as necessidades do bairro onde a moradia e as pessoas estão; assim, será possível uma socialização ativa, com a integração das redes sociais e as instituições. Lima ${ }^{4}$ recomenda que o PVC seja mais do que uma restituição de direitos e possa contribuir para a criação de novos direitos a partir de uma articulação para acesso às políticas públicas em outros setores tais como educação, habitação, trabalho. Venturini ${ }^{20}$ sugere que o trabalho seja em busca de uma coesão social, ou seja, o capital social da comunidade na forma de relações de solidariedade e confiança.

\section{Do capital monetário ao capital social}

A virada do que o dinheiro faz poder enquanto capital monetário para um capital social/afetivo parece ser um desafio. Estar na cidade é uma oportunidade de estabelecer o encontro com o outro nos espaços públicos, mas é no espaço privado, na casa, que o encontro se transforma em uma relação mais íntima. A precariedade do local de moradia pode ser um dificultador no estabelecimento de novos laços afetivos entre os beneficiários do PVC e as pessoas comuns do bairro.

Sobre o desafio desta virada, a diferença de gênero também parece interferir. Os três homens, Zé, Wando e Estevão trazem a questão de recorrer, no presente ou no passado, à prostituição para ter uma relação sexual. Podem abertamente falar como ocorre a experiência acerca da sexualidade, enquanto Janaína quer namorar e casar, Ninha tem namorado, mas não quer casar e Linda não menciona nada a respeito.

As seis pessoas têm em suas histórias de vida, aspectos culturais relevantes para o cotidiano.
Desde a livre profissão de fé e participação em cultos religiosos, até a possibilidade de aquisição de bens musicais (CD, aparelhos de som, por exemplo) e uso do violão, entretanto, relatam vivenciá-las em casa sozinhos ou no CAPS. A precariedade da casa e o exercício da sexualidade e da cultura mostram diferentes aspectos de uma questão comum: as barreiras e possibilidades de estabelecimento de relações, para além dos profissionais de saúde ou do resgate das relações familiares, mas com pessoas do bairro, vizinhos ou que frequentam os mesmos espaços públicos de interesse. Compartilhar o cuidado, avançar na inserção no mundo produtivo e intensificar o trabalho de promoção de novos valores sociais do modo como se relacionar com as pessoas que vivenciam grave sofrimento psíquico ${ }^{20}$, mostramse como possibilidades para a virada do capital monetário para o capital social

\section{Programa de Volta para Cidade: o capital social e a garantia de direitos}

Com base nestas constatações, a atualização deste programa, na perspectiva da desinstitucionalização e no cenário atual de mudanças de rumos das políticas públicas no Brasil para um modelo neoliberal marcado pela necropolítica, deve considerar ter como foco o investimento no capital social e na garantia de direitos. Delgado ${ }^{24}$ elenca algumas medidas que demonstram este caminho de retrocessos: o enfraquecimento das ações de atenção básica com dispensa dos agentes comunitários nas equipes de saúde da família; o aumento de valores para internação psiquiátrica e a abertura de vagas em comunidades terapêuticas; não incentivo para abertura de novos Centros de Atenção Psicossocial; além do retorno de ambulatórios especializados.

Zé e Ninha possuem planos de saúde populares de baixo custo, utilizados para contornar dificuldades de acesso aos serviços públicos de saúde para acompanhamento de um câncer e investigação de um tumor, respectivamente. Pela idade, ambos deveriam ser prioridade em suas unidades básicas de saúde, mas relatam só conseguirem manter exames atualizados quando pagam pelos serviços.

Ninha também tensiona o modo de produção. Primeiro, porque se ocupa dos afazeres domésticos e segundo por que participa do projeto de geração de trabalho e renda em sua cidade, confecciona e vende seus produtos em pontos da cidade. Faz isso porque tem autonomia para transitar pelo território, conhece os bairros e se 
sente bem para ir e voltar, a qualquer hora. Este seu trabalho, no entanto, permanece informal e com baixa remuneração.

Alguns estão endividados, inclusive com contrato de aplicações na instituição financeira que é cliente. Com a possibilidade de compras a crédito e de adesão online a serviços bancários, encontram a dificuldade de manter o orçamento mensal sob controle, com gastos dentro do total de ganhos. Mesmo quando a opção de administrar o recurso foi a mais tradicional possível, em um cofre dentro de casa, encontramos relatos de assaltos às residências. Nota-se a importância de adotar medidas de proteção, seja para evitar exploração, seja para acionar recursos de cuidado no enfrentamento de situações de violência urbana.

Chega-se ao que Rotelli ${ }^{25}$ evidencia: o que se coloca em questão não foi unicamente o manicômio, mas a loucura, como uma produção social. Reposicionando que o combate sempre foi contra o conjunto de aparatos científicos, legislativos, administrativos, culturais e de relações de poder estruturados em torno do que foi considerado como "doença" mas que de fato é um modo de estruturação social. Entender que qualquer construção que toma para si uma transformação de grande proporção como esta também é trazer para a cena a possibilidade de que uma construção de novos valores e modos de se relacionar socialmente não é linear ou progressiva. Insinuase em movimentos dialéticos entre o que se pode avançar e o que retroceder.

Tendo em vista que muros podem ser reconstruídos, é necessário mostrar o que foi possível e apontar o que pode ser ampliado. A intersetorialidade se mostra como campo de investimentos, as vivências descritas acima exemplificam demandas para articulações em rede, ainda dentro da saúde e também com outros setores como habitação, renda, trabalho, segurança e justiça.

A aproximação às histórias por meio das narrativas pareceu uma alternativa necessária para ouvir as pessoas que estão diretamente envolvidas neste processo de desinstitucionalização. A perspectiva hermenêutica-dialética permitiu uma análise da historicidade destas histórias, ao mesmo tempo tomá-las como narrativas a-históricas e que possibilitam apontar caminhos distintos para um futuro possível e também incerto que busca novos horizontes.

\section{Considerações finais}

A inclusão no programa reivindicou registro civil e o direito à vida em sociedade. $\mathrm{O}$ acesso a bens $\mathrm{e}$ serviços parecem ser contingentes aos territórios e as relações sociais estabelecidas. Resgatar estes dois aspectos permitiu ir além do recebimento de recursos, tendo a autonomia, a contratualidade e o estabelecimento de novas relações como principais indicadores de uma vida digna, em liberdade.

Habitar a cidade mostra-se, a partir dessas narrativas, como processo de reabilitá-la, como apontou Venturini ${ }^{23}$. Os desafios são aqueles presentes nos modos de vida periféricos e urbanos: a violência e a precarização de trabalho, moradia, lazer, cultura.

No âmbito individual, o envelhecimento agravado pela vivência de isolamento social traz desafios e se faz presente no jogo de forças entre as relações de apoio, estabelecidas em sua maioria com profissionais de saúde e quando existe com outras pessoas, com baixo nível de afeto e intimidade e as relações de exploração estabelecidas, principalmente com instituições financeiras que podem levar a uma menor possibilidade de conquista do capital social e a garantia de direitos humanos.

Do ponto de vista da gestão do programa, percebemos alguns desafios para o desenvolvimento e a expansão do PVC. Acerca do desenvolvimento, consideramos importante as equipes construírem estratégias de apoio a administração dos recursos e da guarda de documentos, apenas quando definido em conjunto em seus projetos terapêuticos singulares. Quanto à expansão, a baixa quantidade de pessoas assistidas pelo PVC reflete, muitas vezes, a morosidade dos processos de desinstitucionalização e relativo desconhecimento de estratégias para acessar direitos, como a possibilidade do registro tardio, necessários para providenciar documentação e abertura de contas. Nestes casos, a designação de uma referência local para o programa, como previsto pela regulamentação do PVC, ou de uma equipe de desinstitucionalização, como previsto pela portaria $2840 / 14^{26}$, podem colaborar para estabelecer ritmos mais próximos às necessidades reais das pessoas.

Frente ao cenário desafiador imposto pelos desmontes do governo federal, percebe-se lugares de resistência e enfrentamento. Recomenda- 
se estudos que tenham como protagonista os usuários e usuárias dos serviços e que possam ser o subsídio para tomada de decisão para o investimento público no bem estar social. Além disso, observa-se a importância de investir na difusão de direitos, importantes para potencializar a continuidade de processos como a reabilitação psicossocial.

\section{Colaboradores}

Os três autores contribuíram na concepção, redação e revisão crítica do manuscrito. 


\section{Referências}

1. Brasil. Lei $n^{\circ} 10.708$ de 31 de julho de 2003. Institui o auxílio-reabilitação psicossocial para pacientes acometidos de transtornos mentais egressos de internações. Diário Oficial da União 2003; $1^{\circ}$ ago. 2003.

2. Sade RMS. Portas abertas do manicômio ao território: entrevistas triestinas. Marília: Oficina Universitária; São Paulo: Cultura Acadêmica; 2014.

3. Fundação Oswaldo Cruz (Fiocruz). Inovações e desafios em desinstitucionalização e atenção comunitária no Brasil. Rio de Janeiro: Fiocruz; 2015.

4. Lima SCL. O programa de volta para casa em Fortaleza: o que mudou na vida de seus beneficiários? [dissertação]. Fortaleza: Universidade Estadual do Ceará; 2008.

5. Franco RF, Stralen CJV. Desinstitucionalização psiquiátrica: do confinamento ao habitar na cidade de Belo Horizonte. Psicol Soc [periódico na internet]. 2015 [acessado 2020 jun 29]; 27(2):[cerca de 10p.]. Disponível em: http://dx.doi.org/10.1590/1807-03102015v27n2p312

6. Campos IO. Programa "De Volta para Casa" em um município do estado de São Paulo: suas possibilidades e limites. [dissertação]. Ribeirão Preto: Universidade de São Paulo; 2008.

7. Secretaria de Atenção à Saúde, Departamento de Ações Programáticas Estratégicas. Residências terapêuticas: o que são, para que servem. Brasília: Ministério da Saúde; 2004.

8. Lima SS, Brasil SA. Do Programa de Volta para Casa à conquista da autonomia: percursos necessários para o real processo de desinstitucionalização. Physis [periódico na internet]. 2014 [acessado 2020 jun 29]; 24(1):[cerca de 22 p.]. Disponível em: https://doi. org/10.1590/S0103-73312014000100005

9. Massa PA, Moreira MIB. Vivências de cuidado em saúde de moradores de serviços residenciais terapêuticos. Interface (Botucatu) [periódico na internet]. 2019 [acessado 2020 jun 29]; 23: [cerca de 14p.]. Disponível em: https://doi.org/10.1590/interface.170950

10. Guerrero AVP, Bessoni EA, Cardoso AJC, Vaz BC, Braga-Campo FC, Badaró MIB. O Programa de Volta para Casa na vida cotidiana dos seus beneficiários. Saude Soc [periódico na internet]. 2019 [acessado 2020 jun 29]; 28(3):[cerca de 9p.]. Disponível em: https://doi.org/10.1590/s0104-12902019190435.

11. Bessoni EA, Capistrano A, Silva G, Koosah J, Cruz K, Lucena M. Narrativas e sentidos do Programa de Volta para Casa: voltamos, e daí? Saude Soc [periódico na internet]. 2019 [acessado 2020 jun 29]; 28(3):[cerca de 13p.]. Disponível em: https://doi.org/10.1590/ s0104-12902019190429.

12. Desinstitute, Weber R, organizadora. Painel Saúde Mental: 20 anos da Lei 10.216/01. Brasília: [s.n.]; 2021.

13. Conselho Federal de Psicologia (CFP). Hospitais Psiquiátricos no Brasil: Relatório de Inspeção Nacional. Brasília: CFP; 2019. [acessado 2021 mar 11]. Disponível em: https://site.cfp.org.br/wp-content/uploads /2019/12/549.3_ly_RelatorioInspecaoHospPsiq-ContraCapa-Final_v2Web.pdf

14. Brasil. Emenda Constitucional n ${ }^{\circ} 95$ de 15 de Dezembro de 2016. Altera o Ato das Disposições Constitucionais Transitórias, para instituir o Novo Regime Fiscal, e dá outras providências. Diário Oficial da União. Seção $12016 ; 16 \mathrm{dez}$.
15. Moreira MIB, Guerrero AVP, Bessoni EA. Entre desafios e aberturas possíveis: vida em liberdade no contexto da desinstitucionalização brasileira. Saude Soc [periódico na internet]. 2019 [acessado em 2020 jun 29]; 28(3):[cerca de 5p.]. Disponível em: http:// dx.doi.org/10.1590/s0104-12902019000003.

16. Minayo MCS. O desafio do conhecimento: pesquisa qualitativa em saúde. 13a ed. São Paulo: Hucitec; 2013.

17. Minayo MCS, organizadora. Pesquisa Social: teoria, método e criatividade. $21^{\text {a. }}$ ed. Petrópolis: Editora Vozes Ltda; 2002.

18. Koosah J, Moreira MIB, Braga-Campos FC. Construindo histórias em tessitura lenta: desinstitucionalização e narrativas em pesquisa. Saude Soc [periódico na internet]. 2019 [acessado 2020 jun 29]; 28(3):[cerca de 10p.]. Disponível em: https://doi.org/10.1590/ s0104-129020190428.

19. Mantzavinos C. O círculo hermenêutico Que problema é este? Tempo Social [periódico de internet]. 2014 [acessado 2018 out 13]; 26(2):[cerca de 12 p.]. Disponível em: https://doi.org/10.1590/S010320702014000200004.

20. Venturini EA. Linha Curva: O Espaço e o Tempo da Desinstitucionalização. Tradução de Nilson Moulin. Rio de Janeiro: Editora Fiocruz; 2016.

21. Pitta A, organizadora. Reabilitação Psicossocial no Brasil. São Paulo: Hucitec; 1996.

22. Saraceno B. Libertando identidades: da reabilitação psicossocial à cidadania possível. Belo Horizonte: Te Cora; 1999.

23. Venturini E. "O caminho dos cantos": morar e intersetorialidade na saúde mental. Fractal Rev Psicol [periódico de internet]. 2010 [acessado 2017 ago 1]; 22(3): [cerca de 9 p.]. Disponível em: https://doi. org/10.1590/S1984-02922010000900002

24. Delgado PG. Reforma psiquiátrica: estratégias para resistir ao desmonte. Trab Educ Saude [periódico de internet]. 2019 [acessado 2019 maio 9]; 17(2): [cerca de 4 p.]. Disponível em: https://bit.ly/2I3TrKg.

25. Rotelli F, Leonardis O, Mauri D. Desinstitucionalização. $2^{\mathrm{a}}$ ed. São Paulo: Hucitec; 2001.

26. Brasil. Portaria no 2.840, de 29 de dezembro de 2014. Cria o Programa de Desinstitucionalização integrante do componente Estratégias de Desinstitucionalização da Rede de Atenção Psicossocial (RAPS), no âmbito do Sistema Único de Saúde (SUS), e institui o respectivo incentivo financeiro de custeio mensal. Ministério da Saúde. Gabinete do Ministro. Brasília: MS; 2014b. [acessado 2020 out 15]. Disponível em: http://bvsms.saude.gov.br/bvs/saudelegis/gm/2014/ prt2840_29_12_2014.html.

Artigo apresentado em 29/10/2020

Aprovado em 14/10/2021

Versão final apresentada em 16/10/2021

Editores-chefes: Romeu Gomes, Antônio Augusto Moura da Silva 